\title{
THE USE OF PHYSICAL METHODS IN TREATING RAW MATERIALS OF THE BANSKÁ ŠTIAVNICA REGION
}

\author{
MICHAL LEŠKO, MILAN BÚGEL AND FRIDRICH ZELENÁK \\ Department of Mineral Processing and Environmental Protection, \\ BERG Faculty, Technical University of Košice, 04200 Košice, \\ Slovakia
}

(Received July 18, 1996, accepted October 15, 1996)

\begin{abstract}
Laboratory experiments on beneficiation of feldspar using physical methods are described. The results of the tests in which table, magnetic and electrical separations were used show that it is not possible to reduce the concentration of iron in the final product below $1 \%$. It is thus clear that physico-chemical techniques must be applied.
\end{abstract}

\section{INTRODUCTION}

Problems of treating raw materials for the ceramics manufacture in Slovakia are considerable which is understandable taking into account the existing material basis. This fact, together with the present economic situation in the Banská Štiavnica region initiated activities associated with utilisation of granodiorite as a source of feldspar for the ceramics manufacture in this locality. That is why the task of verifying the amenability of granodiorite was initiated.

The Banská Štiavnica region has been noted for very extensive mining and mineral processing activities during the centuries. In various historical periods the region occupied an important position among the mining centres of the former Austria-Hungary. Various complex ores $(\mathrm{Ag}, \mathrm{Au}, \mathrm{Pb}, \mathrm{Zn}, \mathrm{Cu}$ ) were treated in 
those days. At the present time, the mining activity has been interrupted since verified reserves of $\mathrm{Pb}-\mathrm{Zn}$ ore do not allow effective utilisation. The objective of evaluation the amenability of granodiorite was to revive the above mentioned mining activity in the region.

Term granodiorite denotes igneous rocks being penetrated with mining works in an extensive underground. Neither the localisation not mineralogical composition of the supplied sample was known to the investigators. Chemical analysis of the sample was as follows: $\mathrm{SiO}_{2} 61.45 \%, \mathrm{~K}_{2} \mathrm{O} 4.80 \%, \mathrm{Na}_{2} \mathrm{O} 1.69 \%, \mathrm{CaO} 1.42 \%, \mathrm{MgO}$ $2.23 \%, \mathrm{Fe}_{2} \mathrm{O}_{3} 4.29 \%, \mathrm{Al}_{2} \mathrm{O}_{3} 12.69 \%$, loss on ignition $3.05 \%$. The analysis, together with visual examination indicates that granodiorite has a distinguishable impregnation of pyrite with crystals loosely placed in it.

In order to verify the amenability of the sample, physical separation methods were chosen, such as gravity (shaking table), magnetic and electrostatic separation and their combination. The flotation separation methods were investigated by another research group. This paper will summarise the results obtained using the physical separation techniques as applied to the above specified raw material.

\section{THE AMENABILITY TESTS}

From the averaged sample of the raw material supplied by the mining company Hell Corp., samples were collected for the physical and flotation research. The sample for the physical methods was crushed down by a conical crusher and the crushing roller mill and screened into grain sizes in accordance with the conditions of the experiment.

As optimisation parameters were chosen technological data: weight yield (wy) and Fe-content (weight \%). In this case iron represents the waste - undesirable component. The concentrate can be considered as acceptable when the content of Fe is less than $0.8 \%$.

To evaluate washability of the raw material, classical methods of planning experiments (Gauss method of gradual optimisation) were chosen. Only the results providing the best parameters will be presented in the paper. 
From the results of the measurements errors of particular technological analysis methods were determined so that the results presented in the paper should be interpreted in the statistical sense using the confidence interval $x+\Delta x$ where $\Delta x$ is the value calculated according to the relation $\Delta x=\mathrm{t}_{\alpha, \mathrm{f}}=S x / \sqrt{\mathrm{n}}$. $S x$ is the standard deviation of the measured value $x, n$ is the number of measurements, $t$ is the critical value of the Student test at $\alpha=0.05$ and $f=n-1$ are degrees. If the variation of the results of two parallel experiments was such that Fe content exceeded $2 \Delta x=0.1$, the experiment was repeated. Similarly, when the difference of weight yields in two parallel experiments exceeded $2 \Delta x=3$, the experiment was also repeated.

\section{Separation on a Shaking Table}

The verification experiments were carried out using $<1 \mathrm{~mm}$ grain size. Since this material was not hydraulically pre-classified into equally settling grain sizes, the experiment was such that the equally-settling sizes, subsequently individually separated, were formed at the basic stage. The parameters of the shaking table were as follows: slope: $3^{\circ}$, speed: $110 \mathrm{rpm}$, stroke: $10 \mathrm{~mm}$. There were 10 sampling canisters on the longitudinal side and the head of the shaking table. In the experiments, the first three sampling canisters were considered to represent the concentrate, next five the middlings and the remaining two were the tailings.

By separating the material at given conditions, the following products have been obtained:

$\begin{array}{lcc} & \text { weight yield }(\%) & \text { Fe content (\%) } \\ \text { tailing+pyrite } & 9.3 & 8.4 \\ \text { middlings } & 16.6 & 3.1 \\ \text { concentrate } & 74.1 & 2.4\end{array}$

The total error of the experiment determined from the results of the verification experiments was $\pm 3 \%$ rel.

On the strength of the verification results we decided to carry out next experiments with $<0.15 \mathrm{~mm}$ grain size in order to liberate the grains. Coarser 
grain sizes did not render satisfactory results. Similarly, in this case we used a previously non-classified material and hence in the basic stage it was hydraulically classified into three equally settling sizes and pyrite. The experiment was performed according to flowsheet 1 .

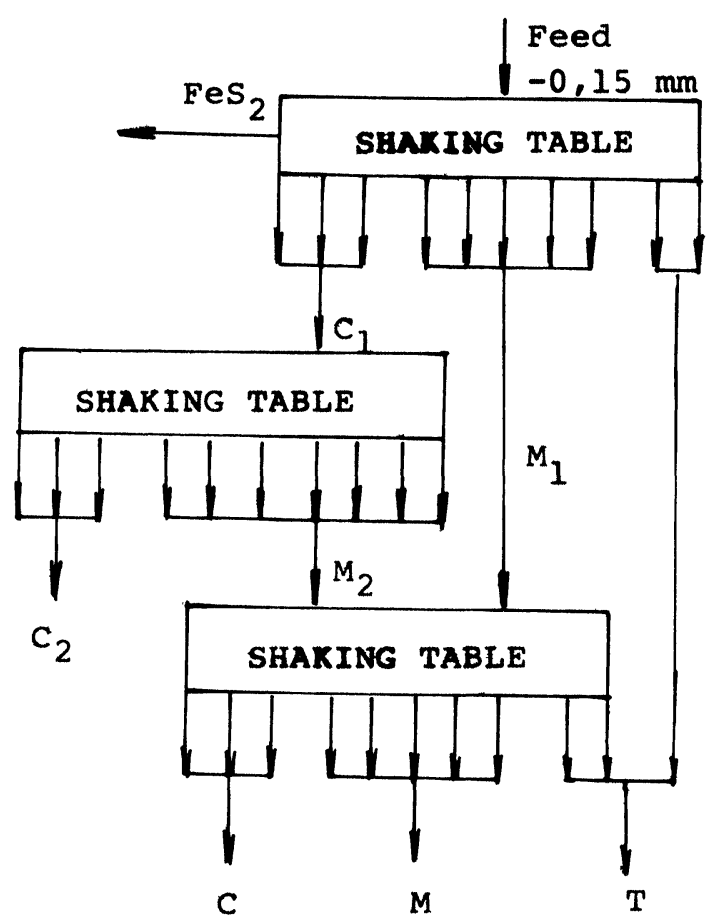

Fig. 1 Flowsheet 1: collection of the shaking table separation products.

By comminution $\mathrm{Fe}$ is concentrated in finer grain size, as follows:

\begin{tabular}{ccc} 
Grain size $[\mathrm{mm}]$ & Weight yield [\%] & Fe content [\%] \\
\hline+0.8 & 24 & 2.48 \\
$0.15-0.8$ & 36 & 2.83 \\
-0.15 & 40 & 3.64
\end{tabular}


By separating the material the following products were obtained:

\begin{tabular}{lcc} 
& Weight yield [5] & Fe content [\%] \\
\hline Pyrite & 4.0 & 12.70 \\
Middlings & 19.5 & 2.93 \\
Concentrate & 70.1 & 2.19
\end{tabular}

In conclusion of this part, it should be stated that separation on the shaking table, under the given conditions, does not provide feldspar concentrates having the content of Fe less than $2 \%$.

\section{Magnetic Separation}

For separation in a magnetic field, the entire spectrum of grain sizes of the material was used. Size fractions $-0.15 \mathrm{~mm},-0.8+0.15 \mathrm{~mm}$ and $+0.8 \mathrm{~mm}$ were separated with a high-intensity magnetic separator $138 \mathrm{~T}-\mathrm{SEM}$ and size $-2+0.8$ $\mathrm{mm}$ and $-2+1 \mathrm{~mm}$ size fractions were separated with a disc electromagnetic separator.

The results are given in Tables 1, 2 and 3. Statistical evaluation of the experiments shows that the variation of $\mathrm{Fe}$ in the feed does not exceed limits of the confidence interval for the mean value. It follows from the calculation of the basic statistical characteristics:

$\mathrm{x}=2.51$

$\mathrm{Sx}=0.034, \mathrm{n}=4, \mathrm{f}=3$, $\mathrm{x} \pm \mathrm{t}_{\alpha, \mathrm{f}} \mathrm{Sx} \sqrt{\mathrm{n}}=2.51 \pm 3,182 \times 0.034 \sqrt{4}=2.51 \pm 0.05 \% \mathrm{Fe}$

It was not desirable to separate $-0.15 \mathrm{~mm}$ size fraction at a higher intensity of the magnetic field because there was no qualitative difference between the separation products. $-2+1 \mathrm{~mm}$ size fraction was separated by using the disc magnetic separator according to flowsheet 2 shown in Figure 2. The results of these experiments are given in Table 4. 
Table 1 The separation results for $+0.8 \mathrm{~mm}$ grain size

\begin{tabular}{|c|c|c|c|c|c|c|c|c|}
\hline \multirow{2}{*}{ Product } & \multicolumn{2}{|c|}{$2 \mathrm{~A}$} & \multicolumn{2}{c|}{$4 \mathrm{~A}$} & \multicolumn{2}{c|}{ 6A } & \multicolumn{2}{c|}{$8 \mathrm{~A}$} \\
\cline { 2 - 9 } & w.y. \% & $\% \mathrm{Fe}$ & w.y. \% & $\% \mathrm{Fe}$ & w.y. \% & $\% \mathrm{Fe}$ & w.y. \% & $\% \mathrm{Fe}$ \\
\hline Non-magnetic & 76,27 & 2,11 & 68,21 & 2,14 & 68,31 & 2,14 & 68,19 & 2,20 \\
magnetic & 23,73 & 3,65 & 31,79 & 3,28 & 31,69 & 3,30 & 31,81 & 3,32 \\
\hline Feed & 100 & 2,48 & 100 & 2,50 & 100 & 2,51 & 100 & 2,56 \\
\hline
\end{tabular}

Table 2 The separation results for $-0.8+0.15 \mathrm{~mm}$ grain size

\begin{tabular}{|c|c|c|c|c|c|c|c|c|}
\hline \multirow{2}{*}{ Product } & \multicolumn{2}{|c|}{$1 \mathrm{~A}$} & \multicolumn{2}{c|}{$2 \mathrm{~A}$} & \multicolumn{2}{c|}{$4 \mathrm{~A}$} & \multicolumn{2}{c|}{$6 \mathrm{~A}$} \\
\cline { 2 - 9 } & w.y. \% & $\%$ Fe & w.y. \% & $\%$ Fe & w.y. \% & $\%$ Fe & w.y. \% & $\%$ Fe \\
\hline Non-magnetic & 77,91 & 2,34 & 72,12 & 2,36 & 62,77 & 2,24 & 59,73 & 2,22 \\
magnetic & 22,09 & 4,51 & 27,88 & 4,13 & 37,23 & 4,05 & 40,27 & 3,88 \\
\hline Feed & 100 & 2,82 & 100 & 2,85 & 100 & 2,91 & 100 & 2,89 \\
\hline
\end{tabular}

Table 3 The separation results for $0.15 \mathrm{~mm}$ grain size

\begin{tabular}{|c|c|c|c|c|}
\hline \multirow{2}{*}{ Product } & \multicolumn{2}{|c|}{$1 \mathrm{~A}$} & \multicolumn{2}{c|}{$2 \mathrm{~A}$} \\
\cline { 2 - 5 } & w.y. \% & $\% \mathrm{Fe}$ & w.y. \% & $\% \mathrm{Fe}$ \\
\hline Non-magnetic & 33,64 & 3,35 & 26,32 & 3,41 \\
magnetic & 66,36 & 3,78 & 37,68 & 3,70 \\
\hline Feed & 100 & 3,64 & 100 & 3,62 \\
\hline
\end{tabular}

Table 4 Results of magnetic separation of $-2+1 \mathrm{~mm}$ grain size

\begin{tabular}{|c|c|c|c|c|c|c|}
\hline \multirow{2}{*}{ Product } & \multicolumn{2}{|c|}{$4 \mathrm{~A}$} & \multicolumn{2}{c|}{$6 \mathrm{~A}$} & \multicolumn{2}{c|}{$8 \mathrm{~A}$} \\
\cline { 2 - 7 } & w.y. \% & $\% \mathrm{Fe}$ & w.y. \% & $\% \mathrm{Fe}$ & w.y. \% & $\% \mathrm{Fe}$ \\
\hline Non-magnetic & 92,21 & & 88,11 & & 85,18 & 2,35 \\
magnetic & 7,79 & 5,61 & 4,1 & 3,48 & 2,93 & 2,75 \\
\hline Feed & 100 & & 92,21 & & 88,11 & \\
\hline
\end{tabular}




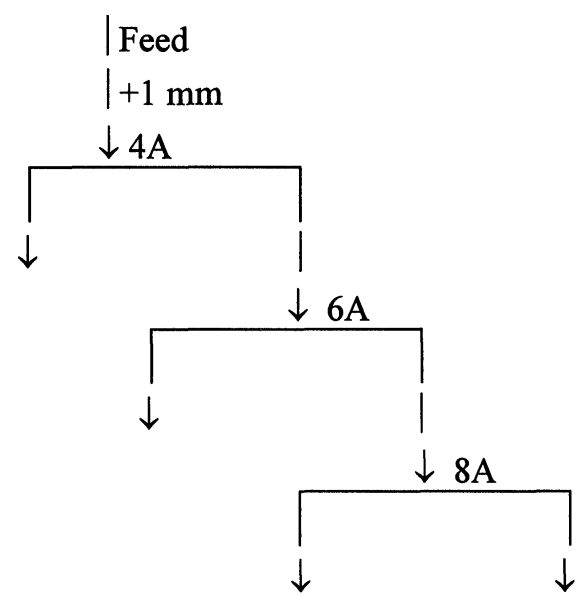

Fig. 2 Magnetic separation flowsheet using the disc separator

\section{Combination of Magnetic and Gravity Separation}

In order to reduce the Fe content in the concentrate, experiments were carried out using magnetic pre-treatment in combination with the shaking table separation, after comminution of the non-magnetic product below $0.15 \mathrm{~mm}$. The experiment proceeded as follows: $-2+0.8 \mathrm{~mm}$ size fraction was separated with the disc magnetic separator at the electric current of $8 \mathrm{~A}$. We obtained:

(i) the non-magnetic product with the weight yield $72.81 \%$ and $2.26 \% \mathrm{Fe}$, and (ii) the magnetic product with the weight yield $27.19 \%$ and $3.46 \% \mathrm{Fe}$.

The non-magnetic product was comminuted to the fineness of $-0.15 \mathrm{~mm}$ by the a friction mill. Using the separation of the shaking table and collecting samples according flowsheet 3 shown in Figure 3, we obtained the following results:

\begin{tabular}{lcc} 
& Weight yield [\%] & Fe content [\%] \\
\hline Pyrite & 4.5 & 12.01 \\
Tailings & 12.2 & 2.17 \\
Middlings & 12.2 & 2.19 \\
Concentrate & 71.1 & 1.67
\end{tabular}




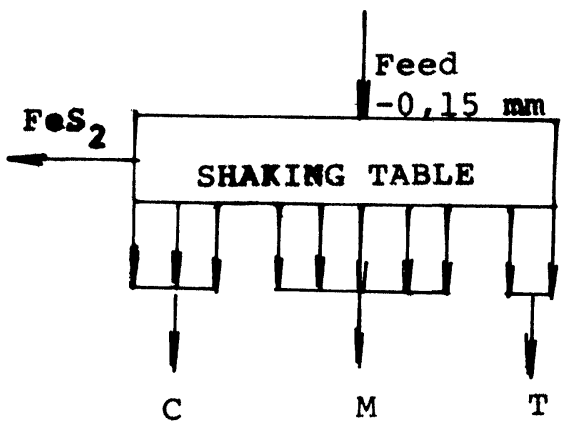

Fig. 3 Flowsheet 3: shaking table separation at the combined treatment

\section{$\underline{\text { Electrostatic Separation }}$}

For separation in electrostatic field, laboratory high-voltage electrostatic separator Sturtevant type $\mathrm{OH}$ was used. The separation was carried out with $-0.8+0.15 \mathrm{~mm}$ size fraction. The first valve was set so that, without voltage, all the material fell into the first container, as can be seen in Figure 4. The second

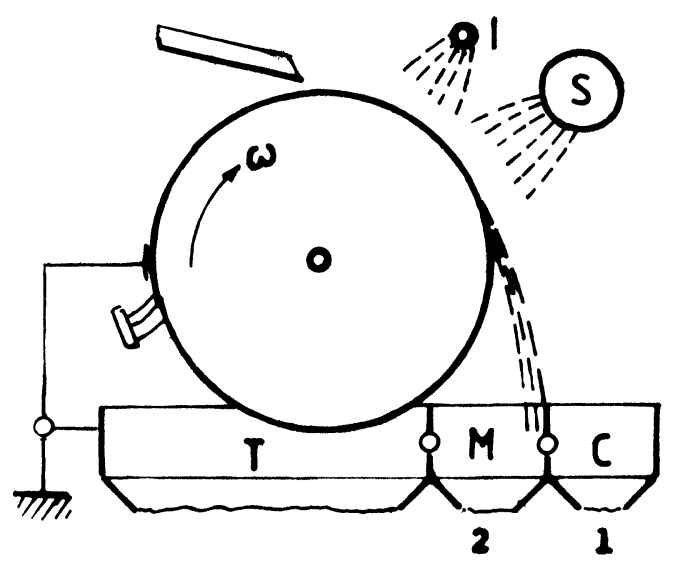

Fig. 4 Laboratory high-voltage electrostatic separator Sturtevant 
valve was in a vertical position and so only dust particles being wiped from the drum and representing only a small fraction $(0.5 \%)$ entered the third container. By analysing the powder after finishing all the experiments, $2.5 \% \mathrm{Fe}$ content was found. The results given in Table 5 do not reflect this fact.

The attained separation results and technical parameters are listed in Table 5. These results show the separation in electrostatic field to be more problematic than that in the magnetic field.

Table 5 Electrostatic separation results

\begin{tabular}{|c|c|c|c|c|c|}
\hline \multirow[t]{3}{*}{ No. } & \multirow{3}{*}{$\begin{array}{l}\text { Parameters } \\
\text { of } \\
\text { experiments }\end{array}$} & \multicolumn{4}{|c|}{ Product } \\
\hline & & \multicolumn{2}{|c|}{1.} & \multicolumn{2}{|c|}{2.} \\
\hline & & w.y. \% & $\% \mathrm{Fe}$ & w.y. \% & $\% \mathrm{Fe}$ \\
\hline \multicolumn{6}{|c|}{ Wire electrode - min. } \\
\hline 1. & $26 \mu \mathrm{A} \quad 8000 \mathrm{~V}$ & 22,0 & 3,2 & 78,0 & 2,80 \\
\hline 2. & $40 \mu \mathrm{A} \quad 15000 \mathrm{~V}$ & 5,7 & 3,8 & 94,3 & 2,63 \\
\hline \multicolumn{6}{|c|}{ Wire electrode - max. } \\
\hline 3. & $15 \mu \mathrm{A} \quad 10000 \mathrm{~V}$ & 64,5 & 2,8 & 35,5 & 3,08 \\
\hline 4. & $40 \mu \mathrm{A} \quad 22000 \mathrm{~V}$ & 30,5 & 2,9 & 69,5 & 2,90 \\
\hline 5. & $70 \mu \mathrm{A} \quad 26500 \mathrm{~V}$ & 10,7 & 3,5 & 89,3 & 2,83 \\
\hline
\end{tabular}

\section{CONCLUSION}

The conducted experiments were centered on verification of possibilities of physical methods of treating a raw material of a given type to the final form of the feldspar concentrate, or as a pre-treatment method prior to flotation. The obtained results confirmed that by using the applied physical methods it is not possible to reduce the $\mathrm{Fe}$ content below $1.6 \%$. When starting from the requirements for the $\mathrm{Fe}_{2} \mathrm{O}_{3}$ content in the feldspar concentrates [2] and the ceramics manufacture [1], we can conclude that the concentrate of the raw material from the combined treatment is suitable for the production of industrial ceramics. 
In conclusion we can state that magnetic separation, under determined conditions, can be included in a technological cycle of a raw material pre-treatment prior to flotation, if the results of the flotation treatment enable the required parameters of the feldspar concentrate to be rendered.

\section{REFERENCES}

[1] J. Hlaváč: The Foundations of the Silicate Technology. SNTL Praha 1981

[2] Czechoslovak Standard (CSN) No. 721370: Feldspar and feldspar raw material.
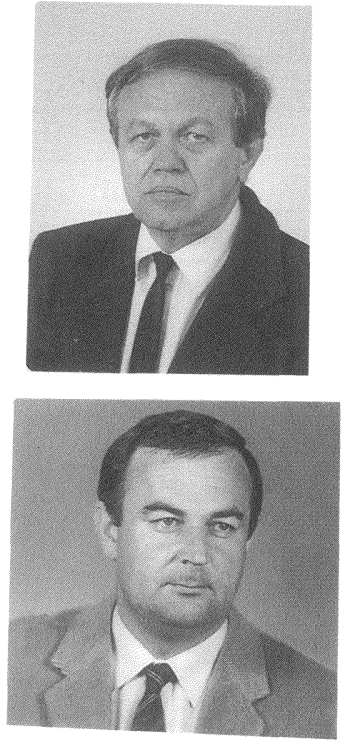

Michal Leško is the Associate Professor of ecotechnology and metallurgy and the member of the staff at the Department of Mineral Processing and Environmental Protection, Faculty of Mining, Ecology, Process Control and Geotechnology (BERG), Technical University of Košice. After graduating from the university Prof. Leško worked in mining industry, specifically at Železnorudné Bane Spišská Nová Ves and Slovenské magnesitové závody, Košice.

Milan Búgel: biography is not available

Fridrich Zelenák: biography is not available

Keywords: magnetic separation, electrostatic separation, gravity separation, feldspar 